\title{
ANALYSIS OF D1853N $A T M$ POLYMORPHISM IN RADIOSENSITIVE PATIENTS WITH CERVICAL CARCINOMA
}

\begin{abstract}
Martin Beránek', Monika Drastíkovál, Simona Paulikován, Igor Sirák², Milan Vošmik², Jiř̌́ Petera ${ }^{2}$
Charles University in Prague, Faculty of Medicine and University Hospital Hradec Králové, Czech Republic: Institute of Clinical Biochemistry and Diagnostics ${ }^{1}$ and Department of Clinical Oncology ${ }^{2}$

Summary: Clinical oncologists have been focusing their efforts on attempting to define risk groups of patients with unusual biological reactions to the recommended therapy regimens using molecular biology techniques. The aims of our study were: (i) to find a design and validate a method for fast and reliable analysis of the D1853N $(5557 \mathrm{G}>\mathrm{A})$ genetic polymorphism in the ATM (ataxia-telangiectasia mutated) gene; (ii) to use side-directed mutagenesis to generate ATM 5557A-positive DNA (reference ATM5557A DNA); and (iii) to analyze a group of patients suffering from cervical carcinoma with adverse responses to radiotherapy. The 5557A variant was found in three of twenty women $(15 \%)$. Our data show that the prevalence of the 5557A allelic variant in cervical cancer subjects with adverse responses after irradiation probably does not differ from the prevalence common in Caucasians. A larger population study should confirm these preliminary results.
\end{abstract}

Key words: ATM; Mutation; Genotyping; Oncology; Diagnostics; Treatment; DNA; PCR; RFLP

\section{Introduction}

Current treatment of human malignancies is based in many cases on a combination of radiotherapy and chemotherapy. Adverse response appearing during the cure impairs the clinical state of patients. Side effects of radiotherapy are partially dependent on genetic differences among individuals. Current efforts of clinical oncologists have focused on defining risk groups of patients with unusual biological reactions to the recommended therapy regimens using molecular biology techniques. Several radiosensitivity candidate genes, e.g. ATM, TGFB1, XRCC1, XRCC3, SOD2, and $h H R 21$, have been identified.

The ataxia-telangiectasia mutated (ATM) gene was localized on the long arm of chromosome 11 (11q22-q23) in 1991 (12). This gene contains 66 exons and its length is $150 \mathrm{~kb}$. The coding sequence is composed of 9168 nucleotides and the encoded ATM protein kinase has a molecular weight of $350 \mathrm{kDa}(19)$. The ATM kinase, a protein with homology to phosphatidyl-inositol-3' kinases at the carboxyl-terminal part, participates in DNA repair, cell-cycle checkpoints regulation, and apoptosis (27). Irradiation induces ATM serine 1981 autophosphorylation, which initiates appropriate signalling cascades in the cell (22).

A number of missense and protein truncation mutations in the ATM gene were observed in somatic cells of ataxia-telangiectasia patients leading to insufficient repairs of double strand breaks and genetic instability $(21,25)$. Heterozygous carriers of ATM mutations are clinically unaffected but predisposed to epithelial cancers, especially breast cancer $(7,24)$. ATM heterozygosity higher than expected in the general population (1-2\%) was described in patients suffering from breast, colon, stomach, pancreas, lung, head, neck, uterus, ovarian, endocrine, and skin tumors, T-cell prolymphocytic leukaemia, and B-cell chronic lymphocytic leukaemia $(1,3,4,6,10,16,17,26,29-31)$. Thus, ATM mutations are considered a risk factor for carcinogenesis.

Tens of neutral genetic variants and polymorphisms of unknown biological significance in ataxia-telangiectasia (AT) families have also been found (20). The D1853N genetic polymorphism (rs1801516; 5557G $>\mathrm{A})$ in $A T M$ exon 39 leads to the substitution of asparagine for aspartic acid at amino acid position 1853. Previously published papers have demonstrated that the presence of the 5557A allelic variant could enhance radiosensitivity of the carriers, and significantly increases the incidence of adverse responses to radiotherapy of prostate and breast cancer $(1,8)$.

The aims of our study were: (i) to find a design and validate a molecular biology method for fast and reliable analysis of the ATM gene; (ii) to use side-directed mutagenesis to generate ATM 5557A-positive DNA (reference ATM5557A DNA); and (iii) to analyse a group of women suffering from cervical carcinoma with adverse responses to radiotherapy.

\section{Material and Methods}

Clinical samples. Twenty patients of Caucasian origin presented with FIGO stage IIB-IIIB epidermoid cervical carcinoma. The median age was 48 years (range 29-61). Nineteen patients were treated with primary concomitant chemoradiotherapy with doses of 48-50 Gy to the small pel- 
vis, 16 of them also received a parametrial boost of 9-14 Gy. In addition, in 13 patients the paraaortic lymphatic nodes were irradiated at 44 Gy. Brachytherapy consisted of 6 fractions with single doses of 4 Gy to point A. Cisplatin with a weekly dosage of $40 \mathrm{mg} / \mathrm{m}^{2}$ was administered concomitantly. In one patient, postoperative radiotherapy with a dose of 60 Gy to the small pelvis was applied following radical hysterectomy. With a median follow-up of 5 years (range 2-9), no patients showed any evidence of the tumour. Low gastrointestinal late complications of grade 3 are present in 4 patients, while grade 3 urological toxicity was observed in 4 patients. The genomic DNA of all the patients was extracted from $200 \mu \mathrm{l}$ of venous EDTA blood by the microcolumn procedure (QIAamp Blood Mini Kit, Qiagen, Germany) with the patients' informed written consent.

Preparation of control samples. DNA of a healthy volunteer was extracted from $200 \mu \mathrm{l}$ of venous blood as described above. The absence of $5557 \mathrm{G}>\mathrm{A}$ alleles was confirmed by DNA sequencing. Consequently, target mutagenesis in the codon 1853 was performed. This three-step process included two independent amplification reactions (PCR I and PCR II) inserting adenine instead of guanine into the coding strain, and thymine into the non-coding strain. The last PCR (PCR III) linked both the semi-products together as illustrated in Fig. 1. All the reactions were carried out in $25 \mu \mathrm{l}$ of reaction mixtures containing $100 \mathrm{ng}$ of DNA (or $5 \mu \mathrm{l}$ PCR I and II products in PCR III), $10 \times$ concentrated PCR buffer with $15 \mathrm{mM}$ magnesium chloride, $200 \mu \mathrm{M}$ each of dNTP (Takara, Japan), $0.4 \mu \mathrm{M}$ of the appropriate pair of primers (Generi Biotech, Czech Republic), and 1U of Taq polymerase (Takara, Japan). After initial denaturation $\left(5\right.$ min at $95^{\circ} \mathrm{C}$ ), PCRs were run for 35 cycles consisting of $30 \mathrm{~s}$ denaturation at $95^{\circ} \mathrm{C}, 30 \mathrm{~s}$ annealing at $50{ }^{\circ} \mathrm{C}$, and $30 \mathrm{~s}$ elongation at $72^{\circ} \mathrm{C}$. The amplification was performed in a Veriti 96-well Thermal Cycler (Applied Biosystems, USA). PCR I amplified the left part (117 bp; forward outer and reverse inner primers were used; the sequences of the primers are provided in Table 1) and PCR II amplified the right part (190 bp; reverse outer and forward inner primers) of the final product. The whole product ( $286 \mathrm{bp}$ ) was formed using outer forward and reverse primers in PCR III (see Fig. 1). The nucleotide sequence of the final product was confirmed by DNA sequencing.

PCR-restriction fragment length polymorphism analysis (PCR-RFLP). The temperature profile and the composition of the reaction mixture for PCR were similar to those above, except for the primer sequences. The reverse primer (5' - ATT TCT CCA TGA TTC ATT TG $\underline{\text { AT }}$-3') creating a wild-type-allele-specific recognition site for the restriction enzyme (a mismatched base underlined) by PCR amplification has been previously published (14). The forward primer (5'-AAA CTA TTG GGT GGA TTT GTT -3') was proposed using Primer Express Version 2.0 software (Applied Biosystems). $10 \mu \mathrm{l}$ of the product was digested with $10 \mathrm{U}$ of $M b o I$ restriction enzyme (New England BioLabs, USA) at $37^{\circ} \mathrm{C}$ for 16 hours. Digested fragments were electrophoresed on a
$3 \%$ agarose gel. The PCR product ( $117 \mathrm{bp}$ ) was cleaved with the enzyme into two fragments ( $95 \mathrm{bp}$ and $22 \mathrm{bp}$ ) in the case of the wild-type allele. In all samples containing undigested PCR products visible on the gel, DNA sequencing followed. A mixture without any DNA template served as negative amplification control.

DNA sequencing. PCR products were purified by QIAquick PCR Purification Kit (Qiagen) and their nucleotide sequences in both directions were determined with BigDye Terminator v3.1 Cycle Sequencing Kit in Genetic Analyser 3130 (Applied Biosystems) according to the manufacturer's instructions.

Tab. 1: Sequences of outer and inner primers used for target mutagenesis in ATM gene exon 39. Underlined bases have created the $5557 \mathrm{G}>\mathrm{A}$ nucleotide exchange on both strains of PCR products.

\begin{tabular}{|l|l|}
\hline Primer & Sequence $\left(\mathbf{5}^{\prime}-\mathbf{3}^{\prime} \mathbf{)}\right.$ \\
\hline $\begin{array}{l}\text { ATM } \text { outer-forward } \\
(19)\end{array}$ & CATTTTTACTCAAACTATTG \\
\hline $\begin{array}{l}\text { ATM } \text { outer-reverse } \\
(19)\end{array}$ & TCTTAAATCCATCTTTCTCTA \\
\hline ATM inner-forward & GATATTTTACTCCAAÁATACA \\
\hline ATM inner-reverse & TGTATTTTGGAGTAAAATATC \\
\hline
\end{tabular}

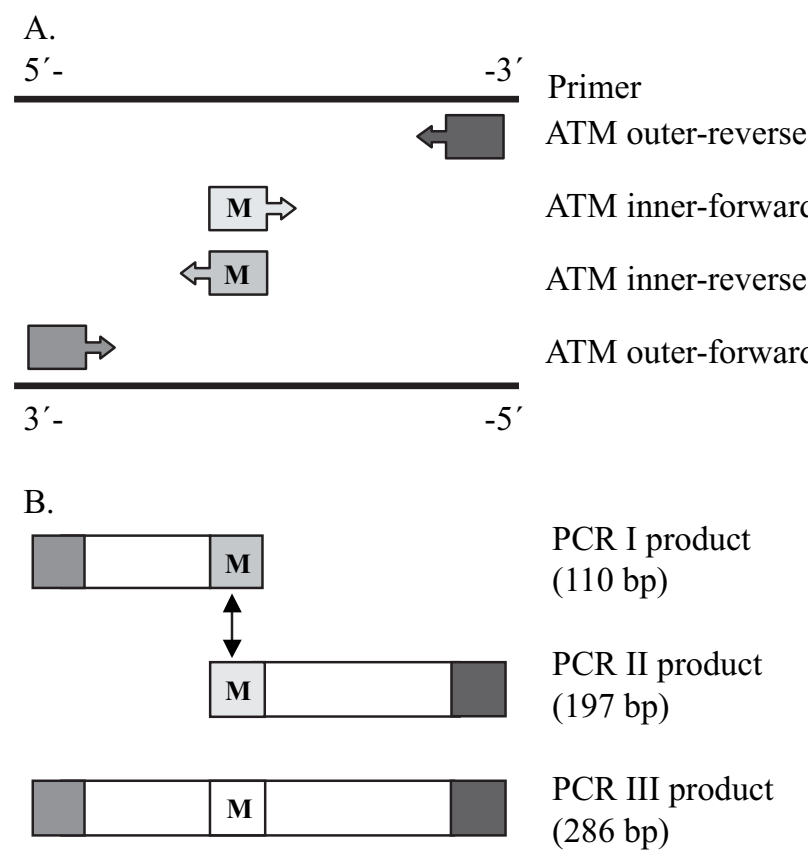

Fig. 1: A design of target mutagenesis in ATM exon 39. Part A shows annealing sites of all used outer and inner primers. Part B shows PCR products generated during three-step target mutagenesis. $\mathrm{M}$ means the target nucleotide exchange $(5557 \mathrm{G}>\mathrm{A})$. 


\section{Results and Discussion}

ATM kinase has a very important role in the maintenance of genome integrity. The ATM gene belongs to conserved parts of human DNA. Table 2 summarizes a sequence similarity of $A T M$ homologues of several animal species and humans in the ATM region covering the human codon 1853. The frequency of the ATM 5557A allelic variant in AT patients is about $18 \%(20)$. A calculated prevalence of $5557 \mathrm{~A}$ homozygotes is 3\% and predicted heterozygosity in AT patients is about $30 \%$. Previously published studies showed that not only AT patients but $15-26 \%$ of the Caucasian population as well carry the $5557 \mathrm{~A}$ allele. $1-2 \%$ of Caucasians are thought to be homozygotes with clinical symptoms of ataxia-telangiectasia $(3,11,17,19)$. The Finnish population reveals a heterozygosity of $37 \%$ and homozygosity of $5 \%$ (28). A low distribution of the 5557A, on the other hand, was described in African-American, Latino, and Japanese population groups $(8 \%, 13-14 \%$ and $6 \%$, respectively) $(5,14)$. The mentioned inter-ethnic discrepancy provides evidence for the geographical heterogeneity of the 5557A allele in the human population.

For DNA analysis, we used a PCR-RFLP method. This approach (if used for a limited number of polymorphic sites in the gene) enables the analysis of more clinical samples per day, cheaper examination, and simplifies the evaluation of the results in comparison with direct DNA sequencing. Firstly, the pair of amplification primers and Dde I restriction enzyme according to Maillet et al. (19) were attempted. Despite the fact that the primers appeared in other papers as well $(3,18)$, we received false negative results of our analyses. Therefore, we have defined our own combination of PCR primers. The reverse primer creating a recognition site for Mbo I restriction enzyme was designed previously.
However, the authors used Rsa I enzyme with a different recognition site than $M b o I(14)$. In all cases, our PCR-RFLP gave completely concordant results with DNA sequencing. Fig. 2 demonstrates the electrophoretic mobility of restriction fragments after $M b o I$ digestion. Fig. 3 provides an example of DNA sequencing.

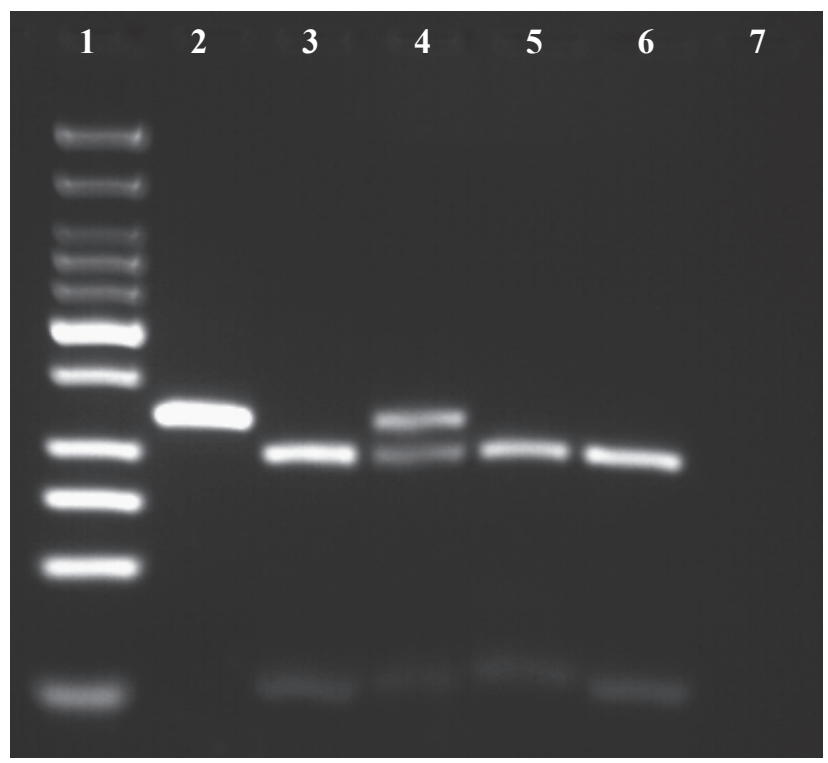

Fig. 2: A slab gel electrophoresis on 3\% agarose gel. Line 1: DNA marker 25 bp (New England BioLabs); line 2: positive control with $5557 \mathrm{G}>$ A mutation in the homozygous state; lines 3, 5 and 6: wild-type patients; line 4: heterozygote patient; line 7: negative control without DNA template. The samples in the lines 2, 3, and 4 were sequenced (Fig. 3).

Tab. 2: Human ATM gene homology according to the National Center for Biotechnology Information (NCBI), USA.

\begin{tabular}{|l|c|c|c|c|c|c|}
\hline Source & $\begin{array}{c}\text { Location } \\
\text { chromo- } \\
\text { some) }\end{array}$ & $\begin{array}{c}\text { NCBI } \\
\text { Accessions }\end{array}$ & DNA Sequence Homology * (5'-3') & \multicolumn{2}{|c|}{ Human Similarity } \\
\cline { 5 - 7 } & 11 & NP_000042.3 & att tta ctc caa gat aca aat gaa tca & nucleotides & amino acids \\
\hline $\begin{array}{l}\text { Homo sapiens } \\
\text { (chimpanzee) }\end{array}$ & 11 & XM_001138999.1 & att tta ctc caa gat aca aat gaa tca & 99,6 & 99,4 \\
\hline $\begin{array}{l}\text { Bos taurus } \\
\text { (cow) }\end{array}$ & 15 & XM_002692978.1 & att cta cta caa gat aca gat gaa tca & 90,7 & 89,9 \\
\hline $\begin{array}{l}\text { Canis lupus } \\
\text { familiaris (dog) }\end{array}$ & 5 & NM_001130828.1 & att tta ctg caa gat aca aat gag tcc & 89,0 & 89,4 \\
\hline $\begin{array}{l}\text { Mus Musculus } \\
\text { (mouse) }\end{array}$ & 9 & NM_007499.2 & gtt tta ctg caa gat aca cat gaa tcg & 85,0 & 84,3 \\
\hline $\begin{array}{l}\text { Rattus norve- } \\
\text { gicus } \text { (rat) }\end{array}$ & 8 & NM_001106821.1 & gtt tta ctc caa gat aca cat gag tcg & 84,1 & 84,2 \\
\hline $\begin{array}{l}\text { Gallus gallus } \\
\text { (chicken) }\end{array}$ & 1 & NM_001162400.1 & act gac atc agt gat aca aat gag tct & $\begin{array}{c}\text { not } \\
\text { analysed }\end{array}$ & $\begin{array}{c}\text { not } \\
\text { analysed }\end{array}$ \\
\hline
\end{tabular}

* Human ATM codon 1853 in bold; nucleotide discrepancy to human DNA in the region around the codon 1853 changing amino acid sequence underlined 

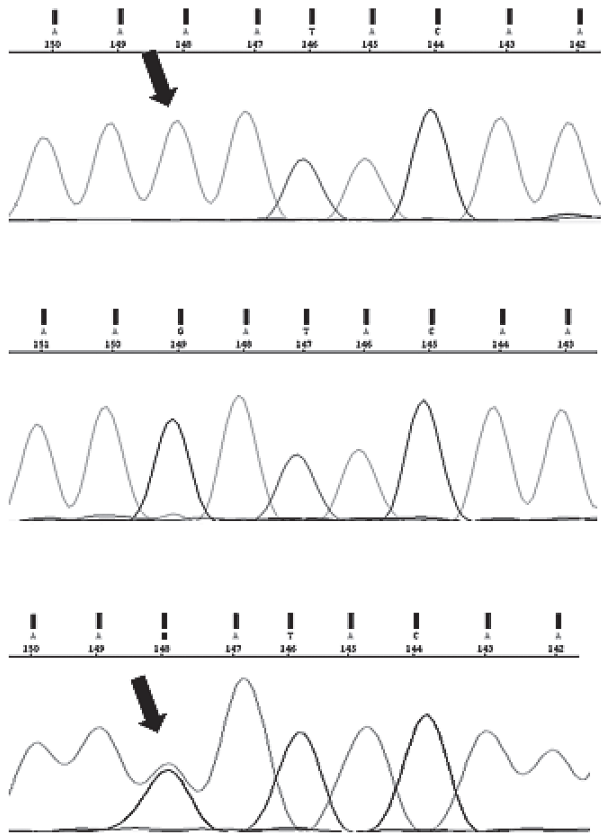

Fig. 3: DNA sequence analyses of $A T M$ exon 39. The upper electrophoreogram shows the nucleotide sequence of the mutant control sample (5557A allele); the middle part presents the homozygous sequence of a wild-type patient (5557G allele); and the lower part shows the sequence of a heterozygous $5557 \mathrm{G}>\mathrm{A}$ patient. Arrows indicate the site of mutation.

It was hypothesized that the 5557A variant could affect an $A T M$ exon 39 splicing enhancer element and influence correct exon 39 splicing (26). The $5557 \mathrm{G}>$ A polymorphism was linked with an increased risk of familial breast cancer, pancreatic cancer and HNPCC-related cancer in $M L H 1$ or MSH2 germ-line mutation carriers $(14,17,18)$. Recently, Gao et al. in a first meta-analysis performed on 4,191 cases and 3,780 controls reported that the $5557 \mathrm{G}>\mathrm{A}$ polymorphism cannot associate with a higher risk of breast cancer development (13).

Several papers also found a positive association between the 5557A allele in a homozygous state and enhanced clinical radiosensitivity. Angele et al. described a higher frequency of the 5557A homozygotes $(6 \%)$ in radiotherapy-sensitive breast cancer cases (3). Andreassen et al. found five heterozygous (12\%) and two homozygous (5\%) 5557A carriers in a group of 41 breast cancer patients with radiation-induced subcutaneous fibrosis (1). Cesaretti et al. observed that the possession of one altered copy of the ATM gene may predispose prostate cancer patients receiving radiotherapy to adverse reactions (8). In our study we analysed the prevalence of the 5557A allele in a small group of radiosensitive women with cervical carcinoma after radiotherapy. The 5557A heterozygosity was identified in three of twenty cases $(15 \%)$. No homozygote was found. It seems the prevalence of the 5557A allelic variant in cervical cancer subjects with adverse responses after irradiation does not differ from the common population prevalence determined in Caucasians. However, an exact mathematical analysis was not possible because of the low number of probands at this moment, so our preliminary results need confirmation in a larger population of patients.

The published data indicates that the presence of 5557A could not be a sufficient genetic event influencing the optimal dosage of radiotherapy. Other mutations in the ATM gene, e.g. $146 \mathrm{C}>\mathrm{G}, 2119 \mathrm{~T}>\mathrm{C}$, IVS10-6T $>\mathrm{G}, 7271 \mathrm{~T}>\mathrm{G}$, IVS62+60G $>$ A, IVS24-9delT, and IVS38-8T $>C$ have been observed to associate with breast, lung, prostate, oral cavity, pharynx, and skin cancer in some but not all published studies $(2,10,11,14,16,23)$. A wider list of genetic changes occurring in the $A T M$ gene also includes: $378 \mathrm{~T}>\mathrm{A}, 735 \mathrm{C}>\mathrm{T}$, $1066-6 \mathrm{~T}>\mathrm{G}, 1810 \mathrm{C}>\mathrm{T}, 2572 \mathrm{~T}>\mathrm{C}, 3161 \mathrm{C}>\mathrm{G}, 4258 \mathrm{C}>\mathrm{T}$, $4578 \mathrm{C}>\mathrm{T}, 5071 \mathrm{~A}>\mathrm{C}, 5558 \mathrm{~A}>\mathrm{T}, 7390 \mathrm{~T}>\mathrm{C}, \mathrm{IVS} 62+8 \mathrm{~A}>\mathrm{C}$, and many other mutations. In summary, we speculate that there is no unique region in the ATM gene or a single causative allele discriminating the carriers for earlier growth of tumours, or indicating the necessity of an individual approach to radiotherapy.

Taking into account a multistep process of carcinogenesis, some authors tried to define the importance of the ATM kinase in double-strand break DNA repair and the number of genetic changes observed in the ATM gene as "risk ATM haplotypes" with a predisposition for cancer development. The 5557A allele was found to be in strong linkage disequilibrium with the IVS38-8T $>C$ ATM variant (in cis position) in breast and prostate cancer $(2,14,15)$. Other authors, however, did not support any association between these mutations and breast cancer (28). Kim et al. described the role of specific haplotypes in the ATM gene in the development of lung cancer in the Korean population (16). Angele et al. reported that the specific ATM haplotype containing the rare alleles IVS22-77T $>\mathrm{C}$ and IVS48+238C $>\mathrm{G}$ is more frequent in breast cancer, especially in homozygote combination (3). The same papers have shown that the presence of IVS22-77T $>$ C/IVS48 $+238 \mathrm{C}>\mathrm{G}$ composed heterozygosity in breast cancer could be associated with a radio-protective effect against fibrosis in normal tissue after irradiation. We believe these observations should clearly reveal how ATM polymorphisms influence abnormal radiosensitivity in the patients.

Several studies have also demonstrated possible functional relationships between $A T M$ variants and polymorphic sites in other genes, especially in $A P E X 1, h H R 21, O G G 1$, $P O L B, R A D 54 L, R E C Q L, T G F B 1, S O D 2, X P F, X R C C 1$, $X R C C 2$, and $X R C C 3(1,17)$. Cortez et al. presented functional interactions between ATM and BRCA1 proteins (9). Maillet et al. found the association of the $5557 \mathrm{G}>\mathrm{A}$ polymorphism with a higher incidence of colorectal cancer in MLH1 or $M S H 2$ germ-line mutation carriers mentioned above (18). All these "radiosensitivity candidate genes" manifest the complexity of genetic events appearing in the 
process of carcinogenesis and the underlying appearance of adverse tissue reactions after radiotherapy.

\section{Conclusions}

In our study we validated the PCR-RFLP method using the $M b o$ I restriction enzyme. Positive control samples carrying the homozygote 5557A genotype in the ATM gene were successfully constructed. Three of the twenty women $(15 \%)$ in our study suffering from cervical carcinoma with adverse responses to radiotherapy were heterozygotes for the 5557A allelic variant. Thus, our preliminary data show that the prevalence of the 5557A allelic variant in cervical cancer subjects with adverse responses after irradiation probably does not differ from the prevalence common in Caucasians. A larger population study should confirm the preliminary results.

\section{Acknowledgement}

The study was supported by research projects NT113344/2010 and MZO 00179906 from the Ministry of Health, Czech Republic.

\section{List of abbreviations}

5557A allelic variant of the $A T M$ gene

$5557 \mathrm{G}$ wild-type allele of the ATM gene

AT ataxia-telangiectasia

bp base pairs

D1853N substitution of asparagine for aspartic acid at position 1853

Dde I Desulfovibrio desulfuricans

dNTP deoxynucleotide triphospate staging classification in gynaecological oncology proposed by the Federation International de Gynecologie et d'Obstetrique

Gy Gray; unit of irradiation

HNPCC hereditary non-polyposis colon cancer

$\mathrm{kb} \quad$ kilobases

$\mathrm{kDa} \quad$ kilodaltons (molecular weight)

Mbo I Moraxella bovis

NCBI National Center for Biotechnology Information (USA)

PCR polymerase chain reaction

RFLP restriction fragment length polymorphism

Rsa I Rhodobacter sphaeroides

APEX1, ATM, BRCA1, hHR21, MLH1, MSH2, OGG1, POLB, RAD54L, RECQL, SOD2, TGFB1, XPF, XRCC1, $X R C C 2$, and $X R C C 3$ are official names of genes appearing in the Online Mendelian Inheritance in Man (OMIN), Johns Hopkins University and on pages of the HUGO Gene Nomenclature Committee (http://www.genenames.org/).

$146 \mathrm{C}>\mathrm{G}, \quad 378 \mathrm{~T}>\mathrm{A}, \quad 735 \mathrm{C}>\mathrm{T}, \quad 1066-6 \mathrm{~T}>\mathrm{G}, \quad 1810 \mathrm{C}>\mathrm{T}$, $2119 \mathrm{~T}>\mathrm{C}, \quad 2572 \mathrm{~T}>\mathrm{C}, \quad 3161 \mathrm{C}>\mathrm{G}, \quad 4258 \mathrm{C}>\mathrm{T}, \quad 4578 \mathrm{C}>\mathrm{T}$, $5071 \mathrm{~A}>\mathrm{C}, \quad 5557 \mathrm{G}>\mathrm{A}, \quad 5558 \mathrm{~A}>\mathrm{T}, \quad 7271 \mathrm{~T}>\mathrm{G}, \quad 7390 \mathrm{~T}>\mathrm{C}$,
IVS10-6T $>$ G, IVS24-9delT, IVS38-8T $>$ C, IVS62+8A $>C$, IVS62+60G $>A$ are sequence variants in the $A T M$ gene described according to the Nomenclature for the Description of Sequence Variants (http://www.hgvs.org/mutnomen/).

\section{References}

1. Andreassen CN, Overgaard J, Alsner J. ATM sequence variants and risk of radiation-induced subcutaneous fibrosis after post-mastectomy radiotherapy. Int J Radiat Oncol Biol Phys 2006; 64:776-83.

2. Angele S, Falconer A, Edwards SM, et al. ATM polymorphisms as risk factors for prostate cancer development. Brit J Cancer 2004; 91:783-7.

3. Angele S, Romestaing P, Moullan N, et al. ATM haplotypes and cellular response to DNA damage: Association with breast cancer risk and clinical radiosensitivity. Cancer Res 2003; 63:8717-25.

4. Bernstein JL, Teraoka S, Haile RW, et al. Designing and implementing quality control for multi-center screening of mutations in the ATM gene among women with breast cancer. Hum Mutat 2003; 542-50.

5. Bretsky, P., Haiman CA, Gilad S, et al. The relationship between twenty missense ATM variants and breast cancer risk: the multiethnic cohort. Cancer Epidemiol Biomarkers Prev 2003; 12:733-8.

6. Bullrich F, Rasio D, Kitada S, et al. ATM mutations in B-cell chronic lymphocytic leukemia. Cancer Res 1999; 59:24-7.

7. Cavaciuti E., Lauge A., Janin N., et al. Cancer risk according to type and location of ATM mutation in ataxia-telangiectasia families. Genes C8. Cesaretti JA, Stock RG, Lehner S, Atencio DA, Bernstein JL, Stone NN. ATM sequence variants are predictive of adverse radiotherapy response among patients treated for prostate cancer. Int J Radiat Oncol Biol Phys 2005; 61:196-202.

9. Cortez D, Wang Y, Qin J, Elledge SJ. Requirement of ATM-dependent phosphorylation of BRCA1 in the DNA damage response to double-strand breaks. Science $1999 ; 286: 1162-6$.

10. Dombernowsky SL, Weischer M, Allin KH, Bojesen SE, Tybjaerg-Hansen A, Nordestgaard BG. Risk of cancer by ATM missense mutations in the general population. J Clin Oncol 2008; 26:3057-62.

11. Dork T, Bendix R, Bremer M, et al. Spectrum of ATM gene mutations in a hospitalbased series of unselected breast cancer patients. Cancer Res 2001; 61:7608-15.

12. Foroud T, Wei S, Ziv Y, et al. Localization of an ataxia-telangiectasia locus to a 3-cM interval on chromosome 11q23: Linkage analysis of 111 families by an international consortium. Am J Human Genet 1991; 49:1263-79.

13. Gao LB, Pan XM, Sun H, et al. The association between ATM D1853N polymorphism and breast cancer susceptibility: a meta-analysis. J Exp Clin Cancer Res 2010; 29:117.

14. Gonzalez-Hormazabal P, Bravo T, Blanco R, et al. Association of common ATM variants with familial breast cancer in a Southern American population. BMC Cancer 2008; 8:117.

15. Heikkinen K, Rapakko K, Karppinen SM, Erkko H, Nieminen P, Winqvist R. Association of common ATM polymorphism with bilateral breast cancer. Int J Cancer $2005 ; 116: 69-72$

16. Kim JH, Kim H, Lee KY, et al. Genetic polymorphisms of ataxia telangiectasia mutated affect lung cancer risk. Hum Mol Genet 2006; 15:1181-6.

17. Li D, Suzuki H, Liu B, et al. DNA repair gene polymorphisms and risk of pancreatic cancer. Clin Cancer Res 2009; 15:740-6.

18. Maillet P, Chappuis PO, Vaudan G, et al. A polymorphism in the ATM gene modulates the penetrance of hereditary non-polyposis colorectal cancer. Int J Cancer 2000; 88:928-31.

19. Maillet P, Vaudan G, Chappuis P, Sappino AP. PCR-mediated detection of a polymorphism in the ATM gene. Moll Cell Probes 1999; 13:67-9.

20. Sandoval N, Platzer M, Rosenthal A, et al. Characterization of ATM gene mutations in 66 ataxia telangiectasia families. Hum Mol Genet 1999; 8:69-79.

21. Savinsky K, Bar-Shira A, Gilad S, et al. A single ataxia-telangiectasia gene with a product similar to PI-3 kinase. Science 1995; 268:1749-53.

22. Shiloh Y. ATM and related protein kinases: safeguarding genome integrity. Nat Rev Cancer 2003; 3:155-68.

23. Stredrick DL, Garcia-Closas M, Pineda MA, et al. The ATM missense mutation p.Ser49Cys (c.146C $>\mathrm{G}$ ) and the risk of breast cancer. Hum Mutat 2006; 27: 538-44.

24. Swift M, Reitnauer PJ, Morrell D, Chase CL. Breast and other cancers in families with ataxia-telangiectasia. New Engl J Med 1987; 316:1289-94.

25. Teraoka SN, Telatar M, Becker-Catania S, et al. Splicing defects in the ataxiatelangiectasia gene, ATM: Underlying mutations and consequences. Am J Hum Genet 1999; 64:1617-31.

26. Thorstenson YR, Roxas A, Kroiss R, et al. Contributions of ATM mutations to familial breast and ovarian cancer. Cancer Res 2003; 63:3325-33.

27. Tíchý A, Vávrová J, Pejchal J, Řezáčová M. Ataxia-telangiectasia mutated kinase (ATM) as a central regulator of radiation-induced DNA damage response. Acta Medica 2010; 53:13-7. 
28. Tommiska J, Jansen L, Kilpivaara O, et al. ATM variants and cancer risk in breast cancer patients from Southern Finland. BMC Cancer 2006; 6:209.

29. Uhrhammer N, Bay J, Pernin D, et al. Loss of heterozygosity at the ATM locus in colorectal carcinoma. Oncol Rep 1999; 6:655-8.

30. Vořechovský I, Luo L, Dyer MJS, et al. Clustering of missense mutations in the ataxia-telangiectasia gene in a sporadic T-cell leukaemia. Nature Genet 1997; 17:96-9.

31. Zhang L, Jia G, Li WM, et al. Alteration of the ATM gene occurs in gastric cancer cell lines and primary tumors associated with cellular response to DNA damage. Mutat Res 2004; 557:41-51.

Received: $19 / 10 / 2010$

Corresponding author:

Accepted in revised form: 25/04/2011

Martin Beránek, Assoc. Prof., PharmD, PhD, Institute of Clinical Biochemistry and Diagnostics, Faculty of Medicine and University Hospital, Sokolská 581, 50005 Hradec Králové, Czech Republic; e-mail: beranek@lfhk.cuni.cz 